\title{
Modeling and multi-objective optimization of a gasoline engine using neural networks and evolutionary algorithms
}

\author{
José D. MARTÍNEZ-MORALES ${ }^{\dagger 1}$, Elvia R. PALACIOS-HERNÁNDEZ ${ }^{2}$, \\ Gerardo A. VELÁZQUEZ-CARRILLO ${ }^{3}$ \\ ( ${ }^{1}$ Faculty of Engineering, Autonomous University of San Luis Potosi, San Luis Potosi 78290, Mexico) \\ ( ${ }^{2}$ Faculty of Science, Autonomous University of San Luis Potosi, San Luis Potosi 78290, Mexico) \\ ( ${ }^{3}$ Mechatronics Department, Monterrey Institute of Technology and Higher Education, Mexico D. F. 01389, Mexico) \\ †E-mail: jdaniel.martinez@alumnos.uaslp.edu.mx \\ Received Jan. 4, 2013, Revision accepted June 17, 2013, Crosschecked Aug. 20, 2013
}

\begin{abstract}
In this paper, a multi-objective particle swarm optimization (MOPSO) algorithm and a nondominated sorting genetic algorithm II (NSGA-II) are used to optimize the operating parameters of a 1.6 L, spark ignition (SI) gasoline engine. The aim of this optimization is to reduce engine emissions in terms of carbon monoxide (CO), hydrocarbons ( $\mathrm{HC})$, and nitrogen oxides $\left(\mathrm{NO}_{x}\right)$, which are the causes of diverse environmental problems such as air pollution and global warming. Stationary engine tests were performed for data generation, covering 60 operating conditions. Artificial neural networks (ANNs) were used to predict exhaust emissions, whose inputs were from six engine operating parameters, and the outputs were three resulting exhaust emissions. The outputs of ANNs were used to evaluate objective functions within the optimization algorithms: NSGA-II and MOPSO. Then a decision-making process was conducted, using a fuzzy method to select a Pareto solution with which the best emission reductions can be achieved. The NSGA-II algorithm achieved reductions of at least $9.84 \%, 82.44 \%$, and $13.78 \%$ for $\mathrm{CO}, \mathrm{HC}$, and $\mathrm{NO}_{x}$, respectively. With a MOPSO algorithm the reached reductions were at least $13.68 \%, 83.80 \%$, and $7.67 \%$ for $\mathrm{CO}, \mathrm{HC}$, and $\mathrm{NO}_{x}$, respectively.
\end{abstract}

Key words: Engine calibration, Multi-objective optimization, Neural networks, Multiple objective particle swarm optimization (MOPSO), Nondominated sorting genetic algorithm II (NSGA-II) doi: 10.1631 jzus.A1300010

Document code: A

CLC number: TK41; TP39

\section{Introduction}

Emissions of air pollutants are known to have a variety of negative effects on public health and natural environment. For several years, emissions of nitrogen oxides $\left(\mathrm{NO}_{x}\right)$, hydrocarbons $(\mathrm{HC})$, carbon monoxide (CO), and particulate matter (PM) have been regulated in different regions of the globe. It has been identified that hydrocarbons are among the most relevant pollutants as they are the major contributor to smog. They are the result of partially burned fossil fuels occurring during the operation of internal combustion engines; this is also known as incomplete

(c) Zhejiang University and Springer-Verlag Berlin Heidelberg 2013 combustion. One of the adverse effects to human health of this pollutant is the reduction of the blood's ability to carry oxygen, which can lead to fatal results in cases of overexposure. Other emissions of interest are $\mathrm{NO}_{x}$, which are generated when the nitrogen contained in the air reacts with oxygen at high temperature and pressure inside the engine. While $\mathrm{NO}_{x}$ are precursors to smog and acid rain, they are also part of greenhouse gases. This means that they trap the heat from solar radiation within our atmosphere provoking a rise in the temperature of the Earth's surface. Thus, engine emissions play a significant role in global warming (Mori, 1997).

In Europe, as in other regions, European emissions standards are created to define the acceptable 
limits for exhaust emissions for new vehicles sold in the European Union (EU). The compliance is determined by running the engine through a standardized test cycle. However, the new standards do not apply to vehicles already in use. The engines of these vehicles should be checked and recalibrated to meet current or planned standards.

Spark ignition (SI) engines have multiple relevant inputs, such as the ignition advance timing, injected fuel mass flow, injection time, engine speed, and in addition air/fuel ratio, and intake manifold absolute pressure (IMAP), among many others that are feedforward or feedback controlled. The outputs of the engine (emissions, drivability) are influenced in a nonlinear way (Guerrier and Cawsey, 2004). Therefore, in the production of a new car, the design of control systems is a very time-consuming task. This requires recycling those engines that have been utilized in the past to power-up new vehicles. An interesting engineering paradox therefore takes place: in order to decrease the design time an old engine is used, but it is necessary to invest a lot of time in modifying the old engine in order to meet the new emission regulations.

In order to optimize the engine operating parameters, a parameter search method should be utilized for many of the engine operating conditions to determine the ideal exhaust emissions. However, when this parameter search method is executed experimentally, it requires a great deal of resources, time, and labor. The optimization of engine parameters by simulation on a computer-based environment is very useful and is replacing the traditional tune-up method. This process is based on modeling the engine responses at a limited set of operating points obtained from experimental measurements using an engine test bench. Artificial neural network (ANN) models have been widely used in several engineering fields due to their ability to find highly nonlinear relationships. This ability makes ANNs appropriate to solve complex nonlinear problems. Many studies of engine calibration have investigated the application of ANNs to model emissions in combustion engines necessary to minimize engine responses (Langouet et al., 2011; Yap et al., 2012). Ismail et al. (2012) reported on an ANN model to predict nine different diesel engine responses including $\mathrm{CO}$ and carbon dioxide $\left(\mathrm{CO}_{2}\right)$.
Ghobadian et al. (2009) used a multilayer perceptron network (MLP) to model the brake power, output torque, specific fuel consumption, and exhaust emissions of a diesel engine. Canakci et al. (2009) used an ANN model to predict the performance and exhaust emissions of a diesel engine including $\mathrm{CO}, \mathrm{NO}_{x}$ and unburned hydrocarbons. However, Saerens et al. (2009) used a mean value model of an internal combustion engine instead of ANN to minimize the fuel consumption by acting on the throttle valve.

Many researchers are conducting tests for the optimization of engine parameters with different types of optimization methods. Particle swarm optimization (PSO) (Kennedy and Heberhart, 1995) is one of the newest techniques within the family of evolutionary optimization algorithms. PSO is a swarm intelligence method that models social behavior to guide swarms of particles towards the most promising regions of the search space and has been extended in order to solve multiple objective optimization problems (Coello and Lechuga, 2002). A multiple objective particle swarm optimization (MOPSO) algorithm is efficient at solving a broad variety of engineering optimization problems due to its fast convergence (Zhao and Cao, 2005; Abido, 2009). On the other hand, genetic algorithms have been used to solve multiobjective optimization problems (MOPs) including minimization of exhaust emissions and fuel consumption. Langouet et al. (2011) used a local linear model tree (LOLIMOT) and multiobjective covariance matrix adaptation evolution strategy (MO-CMA-ES) algorithm to carry out the optimization problem of minimizing emissions of $\mathrm{NO}_{x}, \mathrm{HC}, \mathrm{CO}, \mathrm{CO}_{2}$, also for a diesel engine, utilizing six engine parameters for many engine operating conditions. D'Errico et al. (2011) used the nondominated sorting genetic algorithm II (NSGA-II) in order to find parameters that minimize the break specific fuel consumption and $\mathrm{NO}_{x}$ emissions, as well as maximize the torque of a single cylinder SI engine. Kesgin (2004) increased the efficiency keeping $\mathrm{NO}_{x}$ emissions under a constraint value of a turbocharged natural gas engine. Shi and Reitz (2010) minimized $\mathrm{CO}$, unburned hydrocarbon (UHC), $\mathrm{NO}_{x}$ emissions of a heavy-duty compression ignition engine fueled with diesel and gasoline by using NSGA-II to find optimal combinations of eight optimization parameters. 
Atashkari et al. (2007) preferred NSGA-II to run a Pareto-based optimization of a variable valve-timing engine considering conflicting objectives such as fuel consumption and torque. Alonso et al. (2007) combined ANNs with genetic algorithms to optimize the diesel engine settings reaching important reductions in emissions as $\mathrm{CO}, \mathrm{HC}, \mathrm{NO}_{x}$, break specific fuel consumption (BSFC), and PM for two engine operating conditions.

Although the minimization of engine emissions via computerized optimization processes is not a novel proposal, only a few studies have been reported for gasoline engines (Atashkari et al., 2007; Saerens et al., 2009), while most of the work reported is for diesel engines. In this research project an ascendant approach is performed. In the first instance, ANN models are obtained for each exhaust emission of interest, i.e., $\mathrm{CO}, \mathrm{HC}$, and $\mathrm{NO}_{x}$. The inputs for each model are the engine parameters found in the electronic control unit (ECU) of the engine, which can be modified to change the operating point, and eventually to minimize the corresponding emissions. Then, a minimization process is run using two multiobjective optimization algorithms (MOPSO and NSGA-II). A set of optimal solutions, called Pareto front, is found. The aim of this paper is to show the comparison of emissions reductions obtained by two evolutionary algorithms, and then to make an informed decision on the new values of the engine parameters. A final solution is obtained from the Pareto front by applying a fuzzy method.

It is of a key importance to note that this work intends to contribute in three particular areas. In the first place, having a model that allows predicting the behavior of the internal combustion engine of a vehicle in terms of identified significant pollutants becomes substantial for shortening the time to market for a new engine. This study will show that it has the necessary accuracy to facilitate this conclusion. In the second place, a model that can be run to make a new set point of circulating vehicles in order to make them fulfill the strictest environmental regulations is necessary. It is estimated that testing old vehicles takes a lot of resources while keeping a high level of incertitude in the results. Finally, the adaptation process of a vehicle to a local market can take into account local environmental conditions that affect engine performance, which becomes critical when trying to keep emissions low without compromising performance.

\section{Gasoline engine emissions models}

Using real data obtained from an engine test bench, three neural network models are generated in order to predict engine emissions.

\subsection{Experimental setup}

A four cylinder SI gasoline engine coupled to a hydraulic dynamometer controlling the engine speed in real time is used to conduct the experiments. Exhaust emissions are measured by a gas analyzer type FGA4000XDS from InfraredIndustries ${ }^{\circledR}$ (USA), for 60 different values of the engine angular speed $\left(n_{\text {eng }}\right)$ in revolutions per minute and the angle of the admission throttle valve $\left(\alpha_{\mathrm{th}}\right)$ in $\%$. There are four additional operating parameters whose values are determined for each one of 60 operating conditions. The additional operating parameters are the time of the open state of an injector $\left(t_{\text {inj }}\right)$ in ms measured by a Tektronix ${ }^{\circledR}$ oscilloscope from USA. The injected fuel mass flow $\left(m_{\text {fuel }}\right)$ in $\mathrm{lb} / \mathrm{h}(1 \mathrm{lb}=0.454 \mathrm{~kg})$ is measured by the test bench sensor and conditioned by the software of the SF-902 hydraulic dynamometer from SuperFlow ${ }^{\circledR}$ Corporation in USA. Moreover, the ignition advance timing $\left(\theta_{\mathrm{ign}}\right)$ in degrees $\left(^{\circ}\right)$ relative to \#1 cylinder and the IMAP in $\mathrm{kPa}$ are taken by an on-board diagnostics II (OBD II) system.

The ECU controls all actuators and regulators of the engine according to the measured signals obtained from the sensors. There are prerecorded integrated look up tables in memory for each operating condition that impose the values of the engine operating parameters. These look up tables, called cartography, can be adjusted in order to change the engine response in performance as well as in exhaust emissions. Tables 1 and 2 show the characteristics of the studied internal combustion engine and the hydraulic dynamometer, respectively.

Table 3 shows the taken values for a total of 60 operating points (four angles of the admission throttle valve for 15 engine speed values), which are evaluated in the experimental setup to collect the values of $\mathrm{CO}, \mathrm{HC}$, and $\mathrm{NO}_{x}$ emissions. These 60 engine conditions are selected covering approximately the New European Driving Cycle (NEDC).

In Fig. 1, the equipment to measure engine operating parameters and the engine test-bench used in this study is shown. It consists of a dynamometer 
Table 1 Characteristics of the studied gasoline engine

\begin{tabular}{ll}
\hline \multicolumn{1}{c}{ Characteristic } & \multicolumn{1}{c}{ Value } \\
\hline Model & Z16SE 2005 \\
Maximum power & $100 \mathrm{hp}$ on $5600 \mathrm{r} / \mathrm{min}$ \\
Displacement & $1.597 \mathrm{~L}$ \\
Race & $81.5 \mathrm{~mm}$ \\
Compression ratio & $9.4: 1$ \\
Injection type & Sequential \\
Maximum torque & $138 \mathrm{~N} \cdot \mathrm{m}$ on $3200 \mathrm{r} / \mathrm{min}$ \\
\hline
\end{tabular}

$1 \mathrm{hp}=0.75 \mathrm{~kW}$

Table 2 Characteristics of the hydraulic dynamometer

\begin{tabular}{ll}
\hline \multicolumn{1}{c}{ Characteristic } & \multicolumn{1}{c}{ Value } \\
\hline Absorber type & Water brake \\
Maximum speed & $15000 \mathrm{r} / \mathrm{min}$ \\
Horsepower capacity & $1500 \mathrm{hp}$ \\
Torque capacity & $1200 \mathrm{lb}-\mathrm{ft}$ \\
\hline
\end{tabular}

$1 \mathrm{hp}=0.75 \mathrm{~kW} ; 1 \mathrm{ft}=0.3048 \mathrm{~m}$

Table 3 Engine speeds values evaluated in the experimental setup for each angle of throttle valve

\begin{tabular}{cccc}
\hline \multicolumn{4}{c}{$n_{\text {eng }}(\mathrm{r} / \mathrm{m})$} \\
\hline$\alpha_{\text {th }}=25 \%$ & $\alpha_{\text {th }}=50 \%$ & $\alpha_{\text {th }}=75 \%$ & $\alpha_{\text {th }}=100 \%$ \\
\hline 1500 & 1750 & 2000 & 2250 \\
2500 & 2750 & 2900 & 3000 \\
3100 & 3200 & 3300 & 3400 \\
3500 & 3750 & 4000 & \\
\hline
\end{tabular}

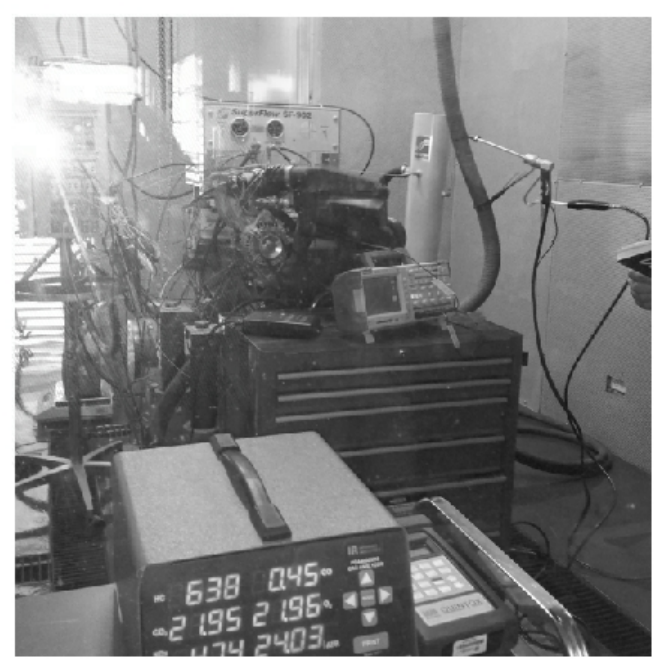

Fig. 1 Experimental setup of internal combustion engine

connected with the crankshaft of the engine. This dynamometer has an electrically controlled throttle actuator to vary the angle of the throttle valve. A fuel canister is used to measure the fuel consumption of the engine in the range from 20 to $270 \mathrm{lb} / \mathrm{h}$.

The ignition advance timing is obtained with a crankshaft position sensor. This sensor indicates that when a notch on the crankshaft goes by and sends a pulse to the ECU, as it is referenced to the top dead point of the piston 1 , it is possible to calculate the angular position of the crankshaft. A manifold absolute pressure (MAP) sensor provides manifold pressure information to the engine ECU. This MAP sensor is also used with an OBD-II PC. A tachometer (magnetic pickup on a 60-tooth gear) measures the engine speed and it is transformed to $\mathrm{r} / \mathrm{min}$. Fig. 2 shows the schematic diagram of the experimental apparatus. Measurements are performed with the engine operating at steady state; this data are recorded $10 \mathrm{~s}$ after setting an operating point to avoid the transient phase.

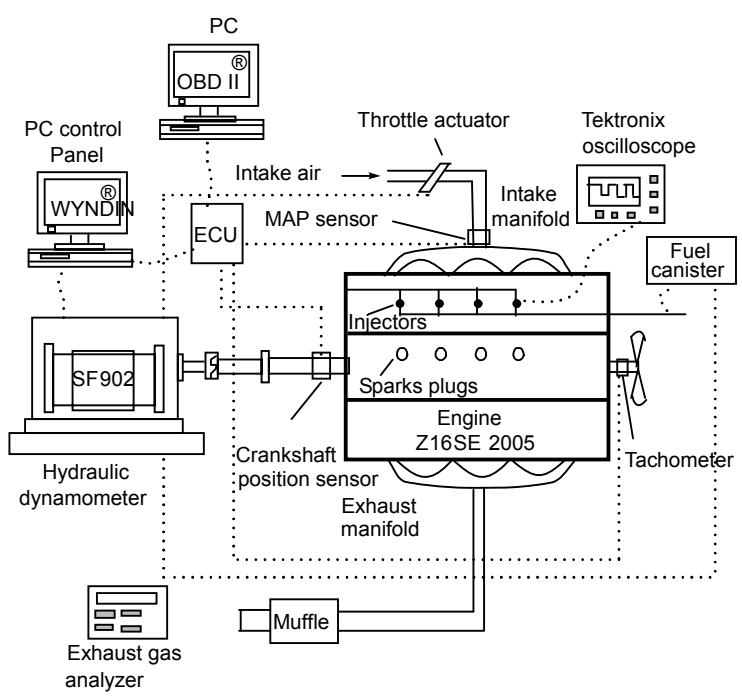

Fig. 2 Schematic diagram of the engine test stand

Before carrying out the first measurement the engine is warmed for $10 \mathrm{~min}$ to ensure that the engine operates in an optimal temperature condition to establish a reference scenario. Table 4 shows some sample data of the studied gasoline engine for four operating points defined at an engine speed of $n_{\text {eng }}=2500 \mathrm{r} / \mathrm{min}$.

\subsection{Neural models of the engine exhaust emissions}

The LOLIMOT approximates a nonlinear function with piece-wise linear models (Hafner et al., 2000; Nelles, 2001). The predicted emission by 
LOLIMOT neural network $y_{\text {pred }}$ is calculated by adding the contributions of all $M$ linear models

$$
y_{\text {pred }}=\sum_{i=1}^{M} y_{\mathrm{LLM}_{i}}(\boldsymbol{x}) \Phi_{i}(\boldsymbol{x}) \text {, }
$$

where $\boldsymbol{x}=\left[x_{1}, x_{2}, \cdots, x_{Q}\right]^{\mathrm{T}}$ are the $Q$ inputs of the network, each neuron represents a local linear model (LLM) and an associated validity function that determines the validity region of the LLM. The outputs of each LLM are given by

$$
y_{\mathrm{LLM}_{\mathrm{i}}}(\boldsymbol{x})=\sum_{j=1}^{Q} p_{i j} x_{j}+p_{i 0},
$$

where $p_{i j}$ and $p_{i 0}$ denote the LLM parameters of the $i$ th hidden neuron. The validity function of the $i$ th hidden neuron corresponds to standard Gaussian function defined as

$$
\Phi_{i}(\boldsymbol{x})=\frac{\mu_{i}(\boldsymbol{x})}{\sum_{j=1}^{M} \mu_{j}(\boldsymbol{x})},
$$

where

$$
\mu_{j}(\boldsymbol{x})=\prod_{i=1}^{Q} \exp ^{-\left(x_{i}-\rho_{i j}\right)^{2} /\left(2 \sigma_{i j}^{2}\right)},
$$

where the centers $\rho_{i j}$ and standard deviations $\sigma_{i j}$ define the position of the center of the peak and the width of the Gaussian functions, respectively. LOLIMOT is an incremental construction algorithm that divides the input space in hyper-rectangles. The validity function of the corresponding LLM is located in their center. The standard deviations $\sigma_{i j}$ are proportional to the size of the hyper-rectangle.

A new LLM is attached to a model partition during every iteration, which is derived from the LLM with the largest local error until the number of iterations is exceeded. The whole model is a network with one hidden layer (Nelles, 2001), and each neuron in this layer produces a linear part of the model. The output layer calculates the weighted sum of the outputs of local linear models. The approximating function generated by the neural network is used to transform the nonlinear behavior of the combustion engine inputs $\boldsymbol{x}$ into the outputs $y_{\text {pred }}$ which approximates the actual output of the engine for each operating condition.

Fig. 3 shows the structure of the used LOLIMOT neural network, whose engine input variables are the engine speed, the angle of the admission throttle valve, the injection time, the injected fuel mass flow, the ignition advance timing, and the IMAP. The output is one of the selected exhaust emissions. Due to the nonlinear relationship of the data, one ANN is constructed for each exhaust emission.

\subsection{Predicted emissions and performance criteria}

In this study, a total of 60 operating conditions are under consideration. Forty of them are used for training of the ANN model, while the other 20 cases

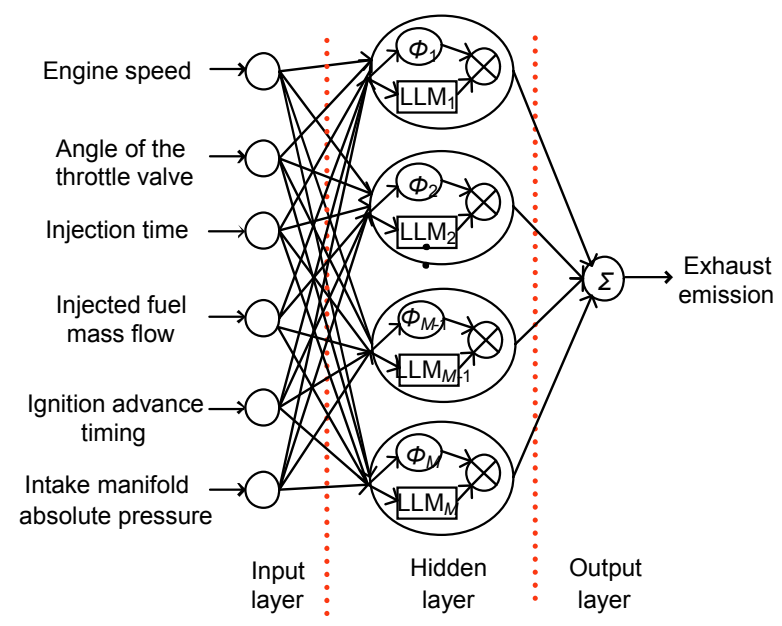

Fig. 3 LOLIMOT-ANN structure used for modeling engine emissions

Table 4 Measurement results of the parameters for an operating point of the gasoline engine

\begin{tabular}{cccccccc}
\hline $\begin{array}{c}\alpha_{\text {th }} \\
\left(n_{\text {eng }}=2500 \mathrm{r} / \mathrm{min}\right)\end{array}$ & $\begin{array}{c}m_{\text {fuel }} \\
(\mathrm{lb} / \mathrm{h})\end{array}$ & $\begin{array}{c}t_{\text {inj }} \\
(\mathrm{ms})\end{array}$ & $\begin{array}{c}\text { IMAP } \\
(\mathrm{kPa})\end{array}$ & $\begin{array}{c}\theta_{\text {ign }} \\
\left(^{\circ}\right)\end{array}$ & $\begin{array}{c}\mathrm{CO} \\
(\%)\end{array}$ & $\begin{array}{c}\mathrm{HC} \\
(\%)\end{array}$ & $\begin{array}{c}\mathrm{NO}_{x} \\
(\%)\end{array}$ \\
\hline $25 \%$ & 18.0 & 9.1 & 187 & 29.5 & 0.58 & 0.0553 & 0.0471 \\
$50 \%$ & 21.0 & 11.6 & 179 & 25.5 & 0.60 & 0.0568 & 0.0507 \\
$75 \%$ & 21.0 & 11.9 & 178 & 25.0 & 0.56 & 0.0567 & 0.0523 \\
$100 \%$ & 22.8 & 13.0 & 178 & 25.0 & 2.55 & 0.0683 & 0.0308 \\
\hline
\end{tabular}


are used for the validation and comparison of the ANN model. It is relevant to mention that a total of nine parameters are monitored during the process. Each operating condition is represented by a dataset. With the aim of conserving the statistical validity of the experiment, it was decided that the datasets for each phase, training as well as testing, would be randomly chosen with a uniform distribution. Thus, all data have the same probability of being selected, ensuring a different selection for each phase. Figs. 4 and 5 present the input and the output training and test datasets for each operating parameter and engine emission, respectively.
Three different criteria are considered in order to evaluate the ANN performance: (1) the mean absolute percentage error (MAPE) that expresses accuracy as a percentage; (2) the correlation coefficient $R^{2}$ used to evaluate the linear relationship between predicted and measured output; and (3) the root mean square errors (RMSE) that are taken into account in order to estimate the ANNs prediction qualities for many architectures of the models. MAPE, RMSE, and $R^{2}$ performances are calculated as (Canakci et al., 2009)

$$
\text { MAPE }=\frac{1}{20}\left[\sum_{i=1}^{20}\left|\frac{y_{\text {meas }_{i}}-y_{\text {pred }_{i}}}{y_{\text {meas }_{i}}}\right|\right] \times 100
$$

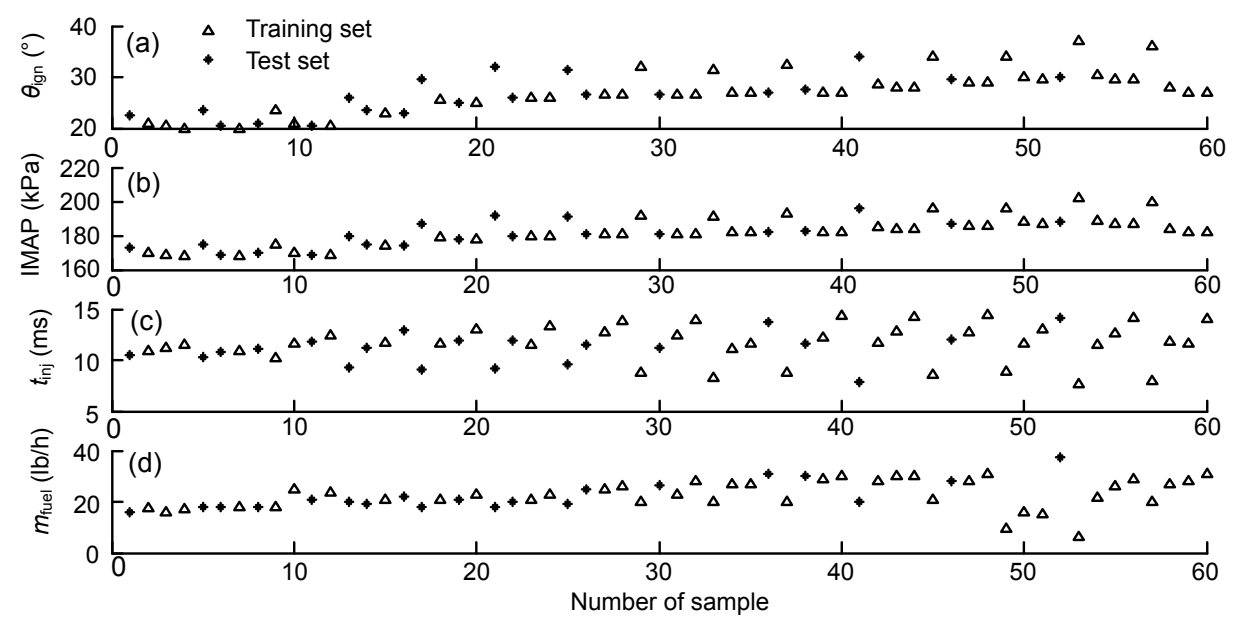

Fig. 4 Engine input parameters for training and test phase (a) Ignition angle; (b) IMAP; (c) Injection time; (d) Fuel mass flow
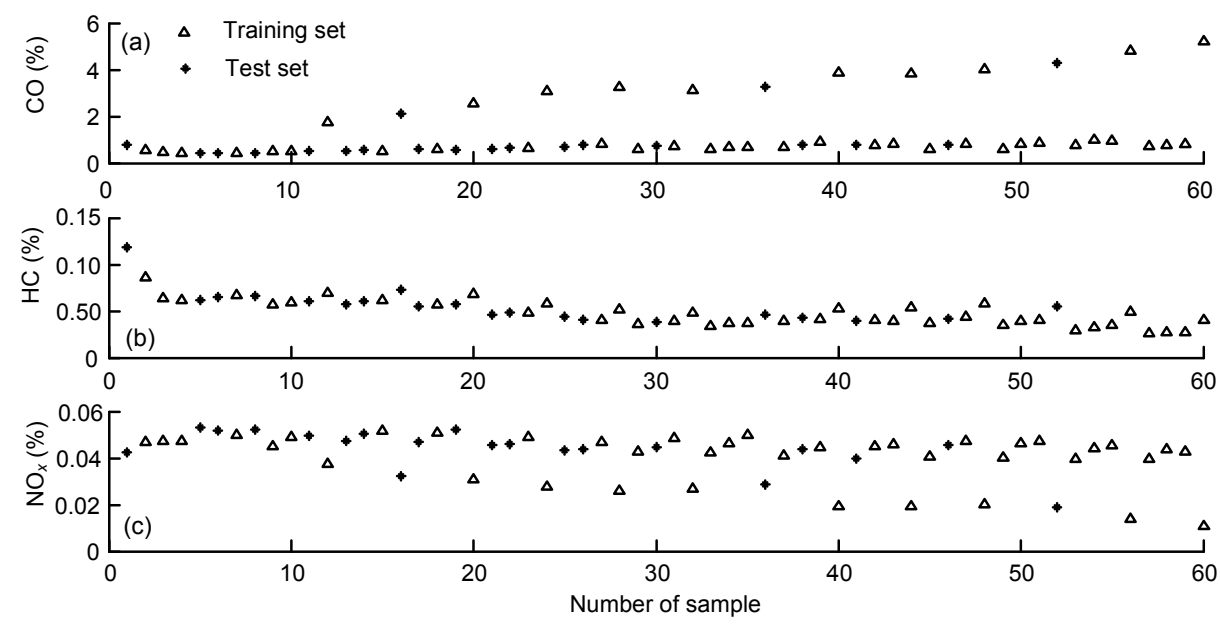

Fig. 5 Engine output emissions for training and test phase (a) $\mathrm{CO}$; (b) $\mathrm{HC}$; (c) $\mathrm{NO}_{x}$ 


$$
\begin{gathered}
\text { RMSE }=\sqrt{\frac{1}{20} \sum_{i=1}^{20}\left[\left(y_{\text {meas }_{i}}-y_{\text {pred }_{i}}\right)^{2}\right]}, \\
R^{2}=1-\left(\frac{\sum_{i=1}^{20}\left(y_{\text {meas }_{i}}-y_{\text {pred }_{i}}\right)^{2}}{\sum_{i=1}^{20}\left(y_{\text {pred }_{i}}\right)^{2}}\right)
\end{gathered}
$$

where $y_{\text {meas }_{i}}$ is a measured value and $y_{\text {pred }_{i}}$ a predicted value by the neural model over all test datasets.
To choose the size of ANNs, MAPE, RMSE and $R^{2}$ are calculated for the testing data for different numbers of hidden neurons as shown in Fig. 6 and Table 5. The RMSE and MAPE are smaller and $R^{2}$ is close to one, with $(6,10,1),(6,9,1)$, and $(6,15,1)$ LOLIMOT neural network architectures for $\mathrm{CO}, \mathrm{HC}$, and $\mathrm{NO}_{x}$ prediction, respectively. The corresponding correlations between recorded and predicted exhaust emissions for these architectures are shown in
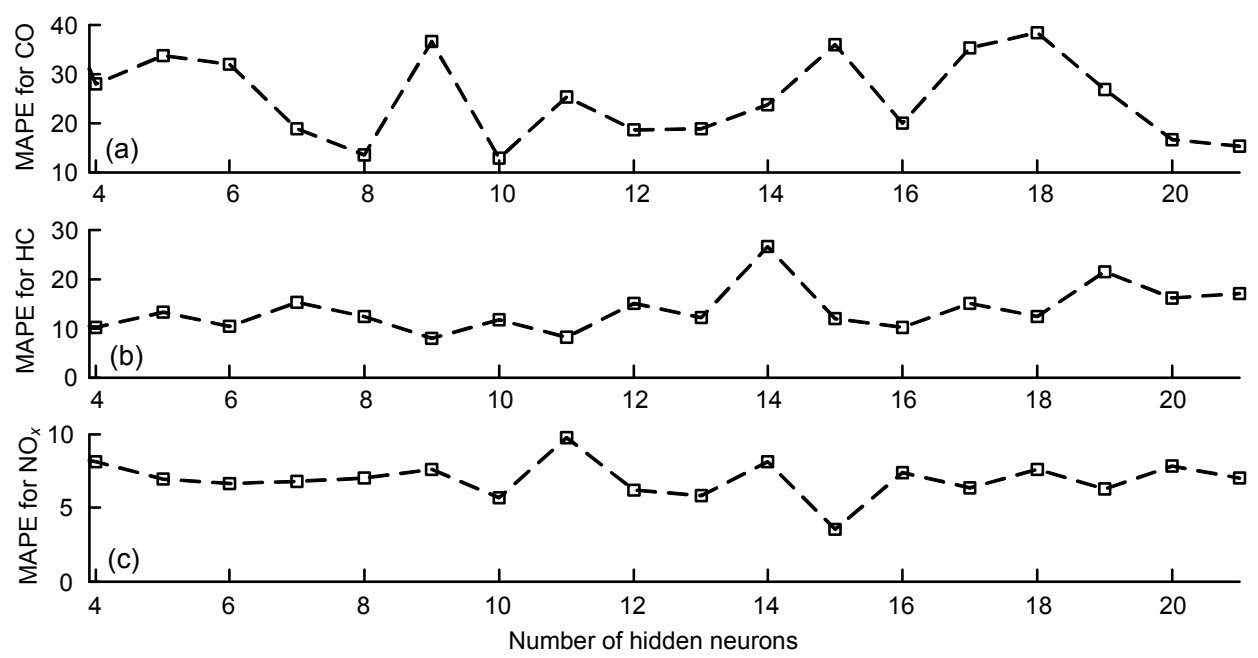

Fig. 6 MAPE behavior of ANNs for different number of neurons in hidden layer: (a) $\mathrm{CO}$, (b) $\mathrm{HC}$, and (c) $\mathrm{NO}_{x}$

\begin{tabular}{|c|c|c|c|c|c|c|}
\hline \multirow{2}{*}{ Number of hidden neurons } & \multicolumn{3}{|c|}{ RMSE } & \multicolumn{3}{|c|}{$R^{2}$} \\
\hline & $\mathrm{CO}$ & $\mathrm{HC}$ & $\mathrm{NO}_{x}$ & $\mathrm{CO}$ & $\mathrm{HC}$ & $\mathrm{NO}_{x}$ \\
\hline 4 & 0.192 & 116.925 & 41.308 & 0.981 & 0.955 & 0.991 \\
\hline 5 & 0.296 & 115.920 & 32.584 & 0.939 & 0.957 & 0.994 \\
\hline 6 & 0.207 & 97.773 & 37.437 & 0.968 & 0.970 & 0.992 \\
\hline 7 & 0.172 & 136.421 & 33.690 & 0.978 & 0.933 & 0.933 \\
\hline 8 & 0.150 & 93.646 & 39.546 & 0.975 & 0.967 & 0.991 \\
\hline 9 & 0.271 & 86.895 & 38.390 & 0.957 & 0.972 & 0.992 \\
\hline 10 & 0.155 & 135.260 & 29.417 & 0.982 & 0.935 & 0.995 \\
\hline 11 & 0.195 & 77.599 & 66.207 & 0.965 & 0.968 & 0.975 \\
\hline 12 & 0.178 & 139.049 & 36.340 & 0.973 & 0.937 & 0.993 \\
\hline 13 & 0.294 & 165.358 & 35.820 & 0.947 & 0.912 & 0.993 \\
\hline 14 & 0.189 & 355.495 & 46.633 & 0.977 & 0.604 & 0.988 \\
\hline 15 & 0.519 & 100.311 & 19.252 & 0.831 & 0.968 & 0.998 \\
\hline 16 & 0.217 & 74.120 & 44.071 & 0.969 & 0.970 & 0.989 \\
\hline 17 & 0.249 & 223.741 & 37.523 & 0.958 & 0.850 & 0.992 \\
\hline 18 & 0.313 & 106.785 & 37.058 & 0.896 & 0.966 & 0.992 \\
\hline 19 & 0.271 & 314.494 & 31.064 & 0.958 & 0.663 & 0.994 \\
\hline 20 & 0.200 & 125.111 & 42.944 & 0.977 & 0.944 & 0.990 \\
\hline 21 & 0.102 & 146.630 & 38.231 & 0.973 & 0.925 & 0.992 \\
\hline
\end{tabular}

Table 5 Performance criteria comparison 
Figs. 7-9. The obtained values in each model are very close to the experimental data. The values of $R^{2}$ are $0.982,0.972$, and 0.998 for testing datasets in the LOLIMOT neural networks models in predicting $\mathrm{CO}$, $\mathrm{HC}$, and $\mathrm{NO}_{x}$, respectively.

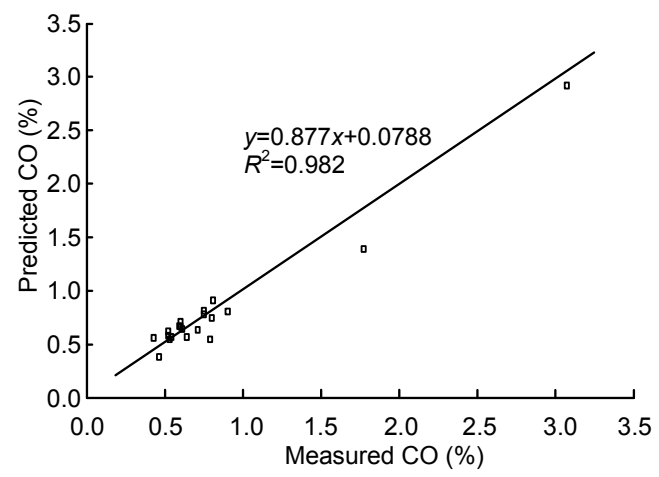

Fig. 7 Correlation between predicted and measured $\mathrm{CO}$

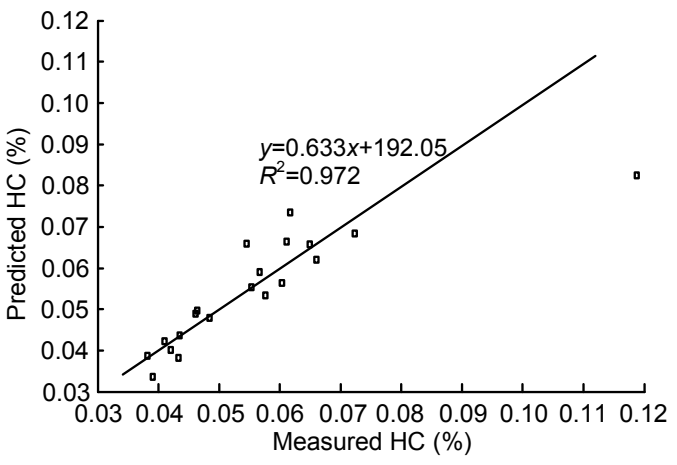

Fig. 8 Correlation between predicted and measured HC

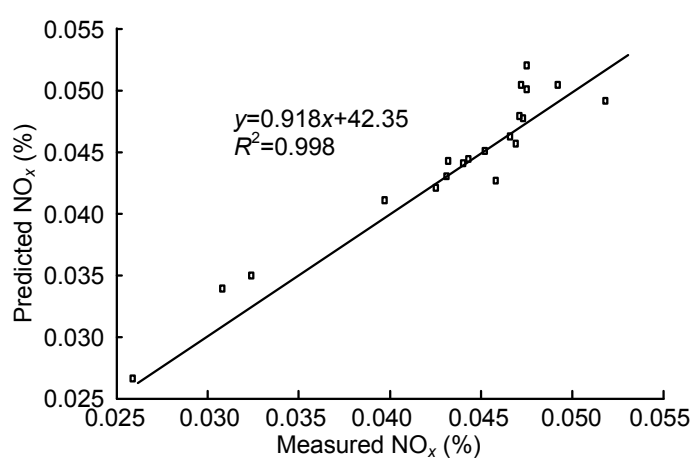

Fig. 9 Correlation between predicted and measured $\mathrm{NO}_{x}$

\section{Multi-objective optimization problem}

\subsection{Definition}

The optimization approach described here uses ANNs as the basis for the evaluation of the objective functions. These are used in the optimization process. Mathematically, the multi-objective optimization problem can be written as

$$
\min _{\substack{\boldsymbol{x} \in \Omega \\ \zeta_{\mathrm{L}} \leq \zeta(\boldsymbol{x}) \leq \zeta_{\mathrm{U}}}}\left\{f_{j}(\boldsymbol{x})\right\}_{j=1}^{N}
$$

where $\Omega$ is the parameter space, $\boldsymbol{x}$ is a point in this space, $N$ is the number of objective functions and $\zeta$ is the vector-valued constraint function with upper and lower limits $\zeta_{\mathrm{U}}$ and $\zeta_{\mathrm{L}}$. The three engine responses considered for minimizing are $\mathrm{CO}, \mathrm{HC}$, and $\mathrm{NO}_{x}$ emissions of the studied gasoline engine. This minimization is done by the variables of injection time $t_{\text {inj }}$, the injected fuel mass flow $m_{\text {fuel }}$, the ignition advance timing $\theta_{\text {ign }}$, and the IMAP. The optimization process is performed for each operating condition defined by engine speed $n_{\text {eng }}$ and the angle of the admission throttle valve $\alpha_{\mathrm{th}}$. The complete details of the multi-objective optimization problem are specified in Table 6.

Table 6 Details of the multi-objective optimization problem

\begin{tabular}{ccccc}
\hline \multicolumn{6}{c}{ Optimization objective: minimize CO, $\mathrm{HC}$, and $\mathrm{NO}_{x}$} \\
\hline \multirow{2}{*}{ Range } & $\begin{array}{c}m_{\text {fuel }} \\
(\mathrm{lb} / \mathrm{h})\end{array}$ & $\begin{array}{c}t_{\text {inj }} \\
(\mathrm{ms})\end{array}$ & $\begin{array}{c}\mathrm{IMAP} \\
(\mathrm{kPa})\end{array}$ & $\begin{array}{c}\theta_{\text {ign }} \\
\left({ }^{\circ}\right)\end{array}$ \\
\hline Min & 6.1 & 7.7 & 168 & 20 \\
Max & 37.2 & 14.4 & 202 & 37 \\
\hline \hline \multirow{2}{*}{ Range } & $n_{\text {eng }}$ & $\alpha_{\text {th }}$ & & \\
& $(\mathrm{r} / \mathrm{min})$ & $(\%)$ & & \\
\hline Min & 1500 & 25 & & \\
Max & 4000 & 100 & & \\
\hline
\end{tabular}

\subsection{Objective functions}

The definition of the objective function is very important for solving an optimization problem, considering that the main objective of the optimization is to reduce $\mathrm{CO}, \mathrm{HC}$, and $\mathrm{NO}_{x}$ emissions, subject to the restrictions of the operating parameters of the studied gasoline engine. The objective functions are defined by

$$
f(\boldsymbol{x})_{i}=\exp \left[\gamma_{i}\left(\frac{e(\boldsymbol{x})_{i}-\mathrm{ME}_{i}}{\mathrm{ME}_{i}}\right)\right]
$$


where $e(\boldsymbol{x})_{i}$ represents the value of the $i$ th emission for the operating parameters $\boldsymbol{x}, \mathrm{ME}_{i}$ represents the maximum value allowed for the $i$ th emission, and $\gamma_{i}$ is a penalty factor. Here $i=1,2,3$, for $\mathrm{CO}, \mathrm{HC}$, and $\mathrm{NO}_{x}$ objective function $f(\boldsymbol{x})_{i}$ respectively. The larger the value of $\gamma_{i}$, the greater the value of the objective function, causing the algorithm to explore other regions in the search space. However, the values of $\gamma_{i}$ are set to 1 for the multi-objective optimization problems treated here by using MOPSO and NSGA-II methods.

\subsection{MOPSO optimization method}

A MOP requires the simultaneous satisfaction of a number of different objective functions, under a number of inequality or equality constraints. MOPs generally give a possibly uncountable set of solutions, whose evaluated vectors represent the best possible trade-offs in the objective function space. In this sense, Pareto optimality is the procedure to establish a hierarchy among the solutions in order to determine whether a solution is really one of the best possible trades-off.

The solution $x^{*}$ is said to be Pareto optimal (minimal) if no other solution can be found to dominate $x^{*}$ using the definition of Pareto dominance. Given two solutions $\boldsymbol{x}^{*}$ and $\boldsymbol{x}$, vector $\boldsymbol{F}\left(\boldsymbol{x}^{*}\right)$ is said to dominate vector $\boldsymbol{F}(\boldsymbol{x})$ (denoted by $\boldsymbol{F}\left(\boldsymbol{x}^{*}\right) \prec \boldsymbol{F}(\boldsymbol{x})$ ) if and only if

$$
\begin{gathered}
\forall i \in\{1,2, \ldots, N\}: f_{i}\left(\boldsymbol{x}^{*}\right) \leq f_{i}(\boldsymbol{x}), \\
\exists i \in\{1,2, \ldots, N\}: f_{i}\left(\boldsymbol{x}^{*}\right)<f_{i}(\boldsymbol{x}) .
\end{gathered}
$$

In MOPSO, a population of potential solutions randomly distributed called particles is created over the search space with random velocity. The positions of the particles are moving towards the positions of the local best element $\boldsymbol{X}_{j}{ }^{*}(t)$ and the global best element $\boldsymbol{X}_{j}^{* *}(t)$. These are selected from the updated set of recorded nondominated solutions. Then, the particles change their positions during generations until a termination criterion is met (Coello and Lechuga, 2002).

The following gives a brief introduction to the operation of the proposed MOPSO algorithm. Consider a swarm of $n$ particles, and each particle is an $m$-dimensional vector, where $m$ is the number of optimized parameters.
1. Initialize the number of iterations until a given limit is reached.

2. Generate randomly $n$ particles, $\boldsymbol{X}_{j}$, with $j=1$, $2, \cdots, n$, where $\boldsymbol{X}_{j}=\left[x_{j, 1}, x_{j, 2}, \cdots, x_{j, m}\right]$.

3. Generate randomly initial velocities of all particles $\boldsymbol{V}_{j}$, with $j=1,2, \cdots, n$, where $\boldsymbol{V}_{j}=\left[v_{j, 1}, v_{j, 2}, \cdots\right.$, $\left.v_{j, m}\right]$.

4. All initial particles are evaluated by using the objective functions.

5 . Define the local best element for each particle as $\boldsymbol{X}_{j}^{*}(0)=\boldsymbol{X}_{j}(0), j=1,2, \cdots, n$.

6. Define a global set $\boldsymbol{S}^{* *}(0)$, with all nondominated solutions.

7. Calculate the distances between $\boldsymbol{X}_{j}(0)$ and the members in $S^{* *}(0)$ by using the Euclidian distance. Define the global best element $\boldsymbol{X}_{i}^{* *}(t)$ as the nearest member in $\boldsymbol{S}^{* *}(t)$ to the $i$ th particle.

8. Set the initial value of the inertia weight $w(0)$.

9. Update the inertia weight $w(t)$ according to

$$
w=w_{\max }-\frac{w_{\max }-w_{\min }}{\text { iter }_{\max }} \times \text { iter }
$$

where iter $_{\max }$ is the number of generations, and iter is the current number of iteration.

10. The $j$ th particle velocity in the $k$ th dimension is updated by

$$
\begin{aligned}
v_{j, k}(t+1)= & w v_{j, k}(t)+c_{1} r_{1}\left(x_{j, k}^{*}(t)-x_{j, k}(t)\right) \\
& +c_{2} r_{2}\left(x_{j, k}^{* *}(t)-x_{j, k}(t)\right),
\end{aligned}
$$

where $c_{1}$ and $c_{2}$ are positive constants, $j=1,2, \cdots, n$, $k=1,2, \cdots, m$, and $r_{1}$ and $r_{2}$ are uniformly distributed random numbers in $[0,1]$.

11. Based on the updated velocities, each particle changes its position according to

$$
x_{j, k}(t+1)=x_{j, k}(t)+v_{j, k}(t+1) .
$$

12. The updated position of each particle $\boldsymbol{X}_{i}(t+1)$ is added to the local set $\boldsymbol{S}_{i}{ }^{*}(t+1)$.

13. Update the global set $\boldsymbol{S}^{* *}(t+1)$ with all the nondominated solutions of $\bigcup_{j=1}^{n} \boldsymbol{S}_{j}^{*}(t+1)$.

14. The nearest member in $S_{j}{ }^{*}(t+1)$ to the $j$ th particle is defined as $\boldsymbol{X}_{j}^{*}(t+1)$. Similarly, the nearest member in the global set $\boldsymbol{S}^{* *}(t+1)$ to the $i$ th particle is 
defined as the global best element $\boldsymbol{X}_{j}^{* *}(t+1)$.

15. If the number of iterations exceeds its limit then stop, else go to step 9 .

\subsection{NSGA-II optimization method}

The NSGA-II method has a diversity preservation mechanism that involves calculation of the so-called crowding distance, which evaluates the density of individuals surrounding a particular individual in the population. Details on NSGA-II can be found in (Deb et al., 2002). It can be summarized as follows:

1. Generate a random population $\boldsymbol{P}_{0}$ of $l$ individuals.

2. Evaluate objective functions for each individual, and sort the population using nondomination order and their crowding distances.

3. Initialize current population $\boldsymbol{P}_{l}=\boldsymbol{P}_{0}$.

4. Apply binary tournament in order to create a mating pool of parents of size $l / 2$ from $\boldsymbol{P}_{l}$ based on Pareto front ranking and crowding distance.

5. Randomly select couples from mating pool and apply bimodal crossover and polynomial mutation operators in order to generate offspring population $\boldsymbol{R}_{l}$ called children of size $l$.

6. Parents and children populations are merged, thus creat a single intermediate population made of $2 l$ individuals; sort them using nondomination order relation.

7. The population is ranked according to the fitness parameters and only the best $l$ individuals are chosen to create the new parents population for the subsequent generation $\boldsymbol{P}_{l+1}$ of size $\boldsymbol{l}$.

8. Go to step 4 with $\boldsymbol{P}_{l}=\boldsymbol{P}_{l+1}$.

In this study, the minimization process finds the optimal solution for each operating condition, defined by engine speed and the angle of the admission throttle valve. For each engine condition the operating parameters are constrained by maximum and minimum values defined by their cartography nominal levels.

\subsection{Fuzzy decision-making}

The multi-objective evolutionary algorithms provide a set of nondominated solutions which form the Pareto front; here a fuzzy-based mechanism is used to find an acceptable solution on the Pareto front. A membership value for the $i$ th objective of the $j$ th solution in the Pareto front is calculated using the membership function given by

$$
m f_{i}^{j}=\left\{\begin{array}{l}
1, \quad \text { if } f_{i} \leq f_{i}^{\min }, \\
\frac{f_{i}^{\max }-f_{i}}{f_{i}^{\max }-f_{i}^{\min }}, \text { if } f_{i}^{\min }<f_{i} \leq f_{i}^{\max }, \\
0, \quad \text { if } f_{i}>f_{i}^{\max },
\end{array}\right.
$$

where $f_{i}$ is the value of the $i$ th objective function, $f_{i}^{\max }$ and $f_{i}^{\mathrm{min}}$ are the maximum and minimum values of the $i$ th objective function, respectively, and $m f_{i}^{j}$ indicates how well the $j$ th nondominated solution is able to satisfy the $i$ th objective. The accomplishment of each Pareto solution with respect to all the $D$ nondominated solutions can be obtained as

$$
m f^{j}=\frac{\sum_{i=1}^{N} m f_{i}^{j}}{\sum_{j=1}^{D} \sum_{i=1}^{N} m f_{i}^{j}} .
$$

The solution with the maximum value of $m f^{j}$ is the solution that can be accepted by the decision-maker.

\section{Results}

For the MOPSO, the inertia weight factor $w$ decreases linearly during the optimization run, $w_{\max }$ and $w_{\min }$ are set to 1.2 and 0.1 , respectively, the amount of particles $n$ is set at 50 , iter $\max _{\max }=10$, and constants $c_{1}=c_{2}=0.5$. Whereas for NSGA-II a population of $l=80$ individuals and $G=20$ generations, with crossover probability $p_{\mathrm{c}}=0.9$ and mutation probability $p_{\mathrm{m}}=0.033$ are considered here. The simulation programs are written in MATLAB and run in a $2.20 \mathrm{GHz}$ Pentium-4 processor with $1 \mathrm{~GB}$ of RAM. To evaluate the convergence of the algorithm, a map of the objective space is created. The Pareto solutions indicating the selection made by the fuzzy decision method are presented in Figs. 10a-10c. For the optimization of the engine operating condition defined by $n_{\text {eng }}=$ $3500 \mathrm{r} / \mathrm{min}$ and $\alpha_{\mathrm{th}}=75 \%$, reductions of $27.56 \%$, $99.67 \%$, and $83.72 \%$ for $\mathrm{CO}, \mathrm{HC}$, and $\mathrm{NO}_{x}$ emissions with NSGA-II are achieved, respectively. Utilizing MOPSO, reductions of $26.6 \%, 99.96 \%$, and $69.97 \%$ for $\mathrm{CO}, \mathrm{HC}$, and $\mathrm{NO}_{x}$ emissions are achieved, respectively. 
After the NSGA-II and MOPSO converged, the values for the emissions corresponding to the obtained Pareto solutions and fuzzy decision-maker (for 10 engine operating conditions) are analyzed as shown in Tables 7 and 8, respectively. As a result of the optimization processes and the reduction percentages, the values of emissions were obtained with the nominal values of the operating parameters (Table 7 and 8). Table 7 shows the reduction for the operating point defined by $n_{\text {eng }}=2900 \mathrm{r} / \mathrm{min}$ and $\alpha_{\mathrm{th}}=25 \%$. This is about $91.44 \%$ with NSGA-II for CO emissions, which is greater than that achieved with

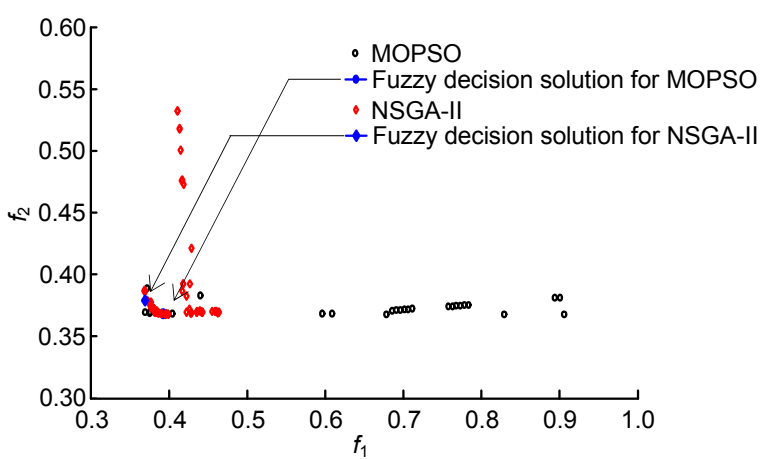

(a)

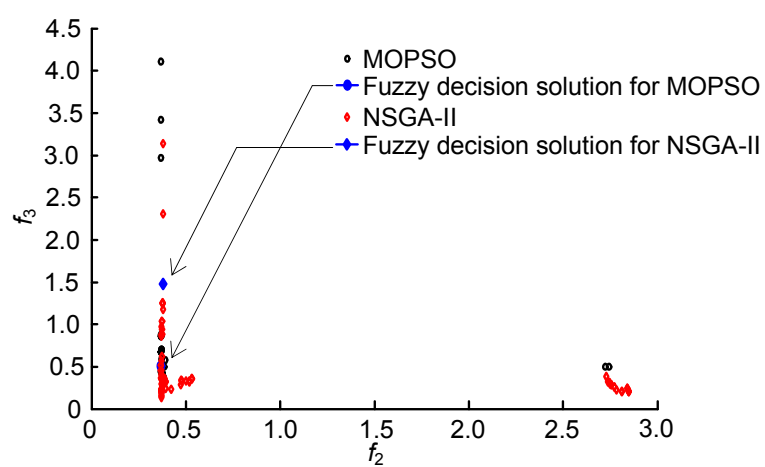

(b)

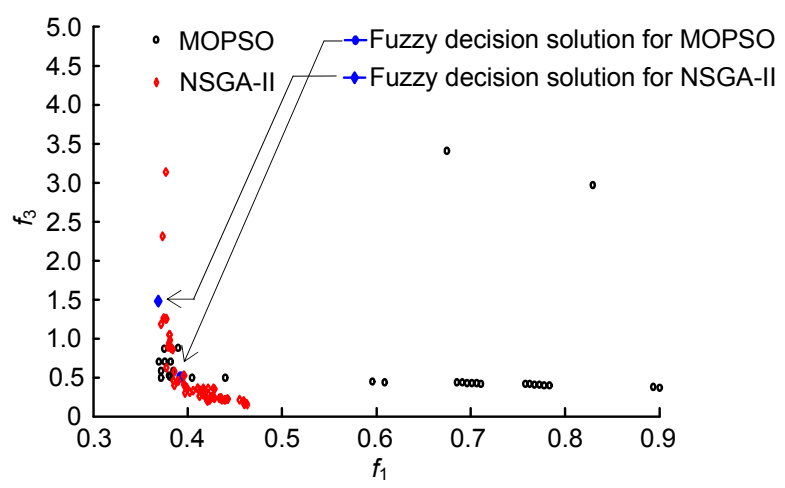

(c)

Fig. 10 Pareto fronts using MOPSO and NSGA-II methods (a) $f_{1}$ vs $f_{2} ;$; (b) $f_{2}$ vs $f_{3}$; (c) $f_{1}$ vs $f_{3}$
Table 7 Comparison of nominal values and NSGA-II optimized values for emissions in 10 operating points

\begin{tabular}{lcll}
\hline & $\mathrm{CO}(\%)$ & $\mathrm{HC}(\%)$ & $\mathrm{NO}_{x}(\%)$ \\
\hline \multicolumn{1}{c}{ Regime $n_{\text {eng }}=2000 \mathrm{r} / \mathrm{min}, \alpha_{\text {th }}=50 \%$} & \\
\hline Nominal & 0.530 & 0.06000 & 0.04900 \\
Best found & 0.446 & 0.00744 & 0.03552 \\
Reduction & 15.770 & 87.580 & 27.505 \\
\hline \hline
\end{tabular}

\begin{tabular}{lcll}
\hline \hline \multicolumn{4}{c}{ Regime $n_{\text {eng }}=2250 \mathrm{r} / \mathrm{min}, \alpha_{\text {th }}=75 \%$} \\
\hline Nominal & 0.520 & 0.06180 & 0.05180 \\
Best Found & 0.157 & 0.00403 & 0.02622 \\
Reduction & 69.630 & 93.470 & 49.370
\end{tabular}

\begin{tabular}{lcll}
\hline \hline \multicolumn{4}{c}{ Regime $n_{\text {eng }}=2500 \mathrm{r} / \mathrm{min}, \alpha_{\mathrm{th}}=100 \%$} \\
\hline Nominal & 2.550 & 0.06830 & 0.03080 \\
Best Found & 0.111 & 0.00258 & 0.01598 \\
Reduction & 95.630 & 96.210 & 48.080 \\
\hline \multicolumn{4}{c}{ Regime $n_{\text {eng }}=2900 \mathrm{r} / \mathrm{min}, \alpha_{\text {th }}=25 \%$} \\
\hline Nominal & 0.710 & 0.04350 & 0.04320 \\
Best Found & 0.253 & 0.00704 & 0.03570 \\
Reduction & 64.170 & 83.800 & 17.340
\end{tabular}

\begin{tabular}{lccl}
\hline \hline \multicolumn{1}{c}{ Regime $n_{\text {eng }}=3000 \mathrm{r} / \mathrm{min}, \alpha_{\mathrm{th}}=50 \%$} & \\
\hline Nominal & 0.730 & 0.03820 & 0.04480 \\
Best Found & 0.630 & 0.00185 & 0.04136 \\
Reduction & 13.680 & 95.150 & 7.670
\end{tabular}

\begin{tabular}{lcll}
\hline \hline \multicolumn{1}{c}{ Regime $n_{\text {eng }}=3100 \mathrm{r} / \mathrm{min}, \alpha_{\mathrm{th}}=75 \%$} & \\
\hline Nominal & 0.710 & 0.03740 & 0.05010 \\
Best Found & 0.405 & 0.00029 & 0.02737 \\
Reduction & 42.930 & 99.190 & 45.351 \\
\hline
\end{tabular}

\begin{tabular}{lcll}
\hline \hline \multicolumn{1}{c}{ Regime $n_{\text {eng }}=3200 \mathrm{r} / \mathrm{min}, \alpha_{\text {th }}=100 \%$} & \\
\hline Nominal & 3.910 & 0.052900 & 0.01920 \\
Best Found & 2.869 & 0.000016 & 0.00576 \\
Reduction & 26.600 & 99.960 & 69.970 \\
\hline
\end{tabular}

\begin{tabular}{lcll}
\hline \hline \multicolumn{4}{c}{ Regime $n_{\text {eng }}=3400 \mathrm{r} / \mathrm{min}, \alpha_{\text {th }}=75 \%$} \\
\hline Nominal & 0.820 & 0.043800 & 0.04740 \\
Best Found & 0.418 & 0.000018 & 0.02783 \\
Reduction & 49.000 & 99.950 & 41.270 \\
\hline \hline \multicolumn{4}{c}{ Regime $n_{\text {eng }}=3500 \mathrm{r} / \mathrm{min}, \alpha_{\text {th }}=50 \%$} \\
\hline Nominal & 0.820 & 0.03900 & 0.046300 \\
Best Found & 0.438 & 0.00252 & 0.000359 \\
Reduction & 46.490 & 93.534 & 99.220 \\
\hline \hline \multicolumn{4}{c}{ Regime $n_{\text {eng }}=3750 \mathrm{r} / \mathrm{min}, \alpha_{\text {th }}=75 \%$} \\
\hline Nominal & 0.960 & 0.034700 & 0.04560 \\
Best Found & 0.753 & 0.000923 & 0.02689 \\
Reduction & 21.540 & 97.330 & 41.022 \\
\hline
\end{tabular}


Table 8 Comparison of nominal values and MOPSO optimized values for emissions in 10 operating points

\begin{tabular}{|c|c|c|c|}
\hline & $\mathrm{CO}(\%)$ & $\mathrm{HC}(\%)$ & $\mathrm{NO}_{x}(\%)$ \\
\hline \multicolumn{4}{|c|}{ Regime $n_{\text {eng }}=2000 \mathrm{r} / \mathrm{min}, \alpha_{\mathrm{th}}=50 \%$} \\
\hline Nominal & 0.530 & 0.06000 & 0.04900 \\
\hline Best Found & 0.393 & 0.00705 & 0.04056 \\
\hline Reduction & 25.730 & 88.247 & 17.220 \\
\hline \multicolumn{4}{|c|}{ Regime $n_{\text {eng }}=2250 \mathrm{r} / \mathrm{min}, \alpha_{\mathrm{th}}=75 \%$} \\
\hline Nominal & 0.520 & 0.06180 & 0.05180 \\
\hline Best Found & 0.103 & 0.00569 & 0.03501 \\
\hline Reduction & 80.125 & 90.782 & 32.407 \\
\hline \multicolumn{4}{|c|}{ Regime $n_{\text {eng }}=2500 \mathrm{r} / \mathrm{min}, \alpha_{\mathrm{th}}=100 \%$} \\
\hline Nominal & 2.550 & 0.06830 & 0.03080 \\
\hline Best Found & 0.551 & 0.0000056 & 0.00174 \\
\hline Reduction & 78.370 & 99.990 & 94.310 \\
\hline \multicolumn{4}{|c|}{ Regime $n_{\text {eng }}=2900 \mathrm{r} / \mathrm{min}, \alpha_{\mathrm{th}}=25 \%$} \\
\hline Nominal & 0.710 & 0.04350 & 0.04320 \\
\hline Best Found & 0.060 & 0.000519 & 0.02590 \\
\hline Reduction & 91.440 & 98.805 & 40.038 \\
\hline \multicolumn{4}{|c|}{ Regime $n_{\text {eng }}=3000 \mathrm{r} / \mathrm{min}, \alpha_{\mathrm{th}}=50 \%$} \\
\hline Nominal & 0.730 & 0.03820 & 0.04480 \\
\hline Best Found & 0.658 & 0.00029 & 0.03106 \\
\hline Reduction & 9.840 & 99.230 & 30.660 \\
\hline \multicolumn{4}{|c|}{ 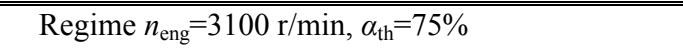 } \\
\hline Nominal & 0.710 & 0.03740 & 0.05010 \\
\hline Best Found & 0.197 & 0.00180 & 0.02689 \\
\hline Reduction & 72.193 & 95.186 & 46.310 \\
\hline \multicolumn{4}{|c|}{ Regime $n_{\text {eng }}=3200 \mathrm{r} / \mathrm{min}, \alpha_{\mathrm{th}}=100 \%$} \\
\hline Nominal & 3.910 & 0.05290 & 0.01920 \\
\hline Best Found & 2.832 & 0.00017 & 0.00312 \\
\hline Reduction & 27.560 & 99.670 & 83.720 \\
\hline \multicolumn{4}{|c|}{ Regime $n_{\text {eng }}=3400 \mathrm{r} / \mathrm{min}, \alpha_{\mathrm{th}}=75 \%$} \\
\hline Nominal & 0.820 & 0.04380 & 0.04740 \\
\hline Best Found & 0.122 & 0.00315 & 0.04086 \\
\hline Reduction & 85.110 & 92.780 & 13.780 \\
\hline \multicolumn{4}{|c|}{ Regime $n_{\text {eng }}=3500 \mathrm{r} / \mathrm{min}, \alpha_{\mathrm{th}}=50 \%$} \\
\hline Nominal & 0.820 & 0.03900 & 0.04630 \\
\hline Best Found & 0.072 & 0.00684 & 0.03275 \\
\hline Reduction & 91.205 & 82.440 & 29.253 \\
\hline \multicolumn{4}{|c|}{ Regime $n_{\text {eng }}=3750 \mathrm{r} / \mathrm{min}, \alpha_{\mathrm{th}}=75 \%$} \\
\hline Nominal & 0.960 & 0.03470 & 0.04560 \\
\hline Best Found & 0.247 & 0.00139 & 0.03344 \\
\hline Reduction & 74.219 & 95.968 & 26.646 \\
\hline
\end{tabular}

MOPSO that reduces emissions only $64.17 \%$. Also for the engine operating condition $n_{\text {eng }}=3100 \mathrm{r} / \mathrm{min}$ and $\alpha_{\text {th }}=75 \%$, a reduction with NSGA-II $(72.19 \%$ for $\mathrm{CO})$ is achieved, which is higher than that with MOPSO which reduces $42.93 \%$ CO emissions. However, with the MOPSO algorithm, greater reductions (41.27\%) for $\mathrm{NO}_{x}$ at the operating point defined by $n_{\text {eng }}=3400$ and $\alpha_{\mathrm{th}}=75 \%$ are achieved, whereas the NSGA-II reduces emissions by only $13.78 \%$. Similarly for the engine operating condition $n_{\text {eng }}=$ $3750 \mathrm{r} / \mathrm{min}$ and $\alpha_{\mathrm{th}}=75 \%$, a reduction of $41.02 \%$ for $\mathrm{NO}_{x}$ emission with MOPSO is reached, while NSGA-II only reduces this emission by $26.64 \%$.

While $n_{\text {eng }}=3750 \mathrm{r} / \mathrm{min}$ and $\alpha_{\mathrm{th}}=75 \%$, the reductions achieved are $96.00 \%$ and $97.33 \%$ for $\mathrm{HC}$ by employing NSGA-II and MOPSO, respectively.

Tables 7 and 8 present reductions of at least $9.84 \%, 82.44 \%$, and $13.78 \%$ achieved for $\mathrm{CO}, \mathrm{HC}$, and $\mathrm{NO}_{x}$ emissions respectively with NSGA-II, while with MOPSO algorithm reductions of at least $13.68 \%, 83.8 \%$, and $7.67 \%$ for $\mathrm{CO}, \mathrm{HC}$ and $\mathrm{NOx}$ emissions are reached, respectively. On the other hand, similar reductions are obtained for $\mathrm{HC}$ emissions with both algorithms in most engine operating conditions, for example reductions of $88.247 \%$ and $87.580 \%$ using NSGA-II and MOPSO respectively for the operating point $n_{\text {eng }}=2000 \mathrm{r} / \mathrm{min}$ and $\alpha_{\text {th }}=50 \%$ are obtained.

It is possible to use the NSGA-II to diminish emissions in some engine operating conditions and the MOPSO method in the rest of the engine conditions, such that the engine is calibrated with parameter values that result in a greater reduction of emissions. Tables 9 and 10 show the optimal configurations of parameters obtained with NSGA-II and MOPSO, respectively, for the 10 operating points of the studied gasoline engine which resulted in the identified emissions reductions.

Thus, the emissions of the gasoline engine can be reduced by updating the engine operating parameters. As a comparison, Alonso et al. (2007) found reductions of $25.8 \%, 36.2 \%$, and $4.4 \%$ for $\mathrm{CO}$, $\mathrm{HC}$, and $\mathrm{NO}_{x}$ emissions; however, this was for a diesel engine at full load operating condition, using the NSGA-II algorithm. Although the case study is not the same, similar reductions are obtained here by using NSGA-II algorithm. 
Table 9 Optimal configurations obtained with NSGA-II method

\begin{tabular}{ccrrcc}
\hline $\begin{array}{c}n_{\text {eng }} \\
(\mathrm{r} / \mathrm{min})\end{array}$ & $\begin{array}{c}\alpha_{\text {th }} \\
(\%)\end{array}$ & $\begin{array}{r}m_{\text {fuel }} \\
(\mathrm{lb} / \mathrm{h})\end{array}$ & $\begin{array}{c}t_{\text {inj }} \\
(\mathrm{ms})\end{array}$ & $\begin{array}{c}\text { IMAP } \\
(\mathrm{kPa})\end{array}$ & $\begin{array}{c}\theta_{\text {ing }} \\
\left({ }^{\circ}\right)\end{array}$ \\
\hline 2000 & 50 & 14.06 & 9.62 & 178.50 & 24.08 \\
2250 & 75 & 6.16 & 9.30 & 181.70 & 31.98 \\
2500 & 100 & 20.41 & 11.33 & 188.20 & 36.16 \\
2900 & 25 & 11.67 & 11.12 & 172.50 & 23.82 \\
3000 & 50 & 18.02 & 8.09 & 173.50 & 35.70 \\
3100 & 75 & 8.71 & 7.92 & 171.10 & 35.00 \\
3200 & 100 & 30.50 & 12.94 & 188.10 & 35.75 \\
3400 & 75 & 6.37 & 8.30 & 182.50 & 35.75 \\
3500 & 50 & 14.53 & 9.00 & 188.10 & 23.64 \\
3750 & 75 & 7.69 & 8.22 & 171.30 & 36.01 \\
\hline
\end{tabular}

Table 10 Optimal configurations obtained with MOPSO method

\begin{tabular}{ccrrcc}
\hline $\begin{array}{c}n_{\text {eng }} \\
(\mathrm{r} / \mathrm{min})\end{array}$ & $\begin{array}{c}\alpha_{\text {th }} \\
(\%)\end{array}$ & $\begin{array}{r}m_{\text {fuel }} \\
(\mathrm{lb} / \mathrm{h})\end{array}$ & \multicolumn{1}{c}{$\begin{array}{c}t_{\text {inj }} \\
(\mathrm{ms})\end{array}$} & $\begin{array}{c}\text { IMAP } \\
(\mathrm{kPa})\end{array}$ & $\begin{array}{c}\theta_{\text {ing }} \\
\left({ }^{\circ}\right)\end{array}$ \\
\hline 2000 & 50 & 7.10 & 14.06 & 188.90 & 24.55 \\
2250 & 75 & 8.69 & 8.66 & 174.00 & 32.04 \\
2500 & 100 & 13.72 & 10.84 & 192.10 & 35.62 \\
2900 & 25 & 14.17 & 9.32 & 179.60 & 24.45 \\
3000 & 50 & 18.32 & 8.16 & 193.00 & 36.42 \\
3100 & 75 & 23.84 & 8.95 & 193.00 & 35.88 \\
3200 & 100 & 34.32 & 11.94 & 179.70 & 33.32 \\
3400 & 75 & 20.66 & 8.80 & 184.21 & 35.73 \\
3500 & 50 & 12.53 & 7.73 & 179.80 & 33.51 \\
3750 & 75 & 18.46 & 11.26 & 179.70 & 35.04 \\
\hline
\end{tabular}

\section{Conclusions}

In this paper, neural network models for exhaust emissions of an SI gasoline engine are used as the basis for the evaluation of the objective functions which are evaluated within the MOPSO and NSGA-II optimization methods. These methods are applied to find a solution to the problem of reducing the emissions of a gasoline engine. LOLIMOT neural networks are utilized to determine suitable predictions for three exhaust emissions under stationary conditions. The carbon monoxide (CO), hydrocarbons $(\mathrm{HC})$ and nitrogen oxides $\left(\mathrm{NO}_{x}\right)$ emissions are modeled and subsequently reduced. Performance of the ANNs has been evaluated by calculating the coefficient of correlation $\left(R^{2}\right)$ and mean absolute percentage error (MAPE). LOLIMOT networks with architectures $(6,10,1),(6,9,1)$, and $(6,15,1)$ are found to be capable to approximate the $\mathrm{CO}, \mathrm{HC}$, and $\mathrm{NO}_{x}$ emissions of the studied gasoline engine, with $R^{2}$ of $0.982,0.972$, and 0.998 , respectively. The MOPSO and NSGA-II methods are performed for 10 engine operating conditions, where the limits in the engine operating parameters are established according to the values in the nominal engine cartography. Important improvements with respect to the nominal manufacturer engine cartographies are observed, reaching reductions of at least $9.84 \%, 82.44 \%$, and $13.78 \%$ for $\mathrm{CO}, \mathrm{HC}$, and $\mathrm{NO}_{x}$ emissions respectively with NSGA-II, although with MOPSO algorithm reductions are reached at least $13.68 \%, 83.8 \%$, and $7.67 \%$ for $\mathrm{CO}, \mathrm{HC}$, and $\mathrm{NO}_{x}$ emissions, respectively. The main limitation of this study is that the determined parameters are only valid for the particular engine used in this case study. However, the methodology can be used to perform the minimization of emissions on hydrogen or biodiesel fueled internal combustion engines.

\section{References}

Abido, M., 2009. Multiobjective particle swarm optimization for environmental/economic dispatch problem. Electric Power Systems Research, 79(7):1105-1113. [doi:10.1016/ j.epsr.2009.02.005]

Alonso, J.M., Alvarruiz, F., Desantes, J.M., Hernandez, L., Hernandez, V., Molto, G., 2007. Combining neural networks and genetic algorithms to predict and reduce diesel engine emissions. IEEE Transactions on Evolutionary Computation, 11(1):46-55. [doi:10.1109/TEVC.2006. 876364]

Atashkari, K., Nariman-Zadeh, N., Golcu, M., Khalkhali, A., Jamali, A., 2007. Modelling and multi-objective optimization of a variable valve-timing spark-ignition engine using polynomial neural networks and evolutionary algorithms. Energy Conversion and Management, 48(3): 1029-1041. [doi:10.1016/j.enconman.2006.07.007]

Canakci, M., Ozsezen, A.N., Arcaklioglu, E., Erdil, A., 2009. Prediction of performance and exhaust emissions of a diesel engine fueled with biodiesel produced from waste frying palm oil. Expert Systems with Applications, 36(5): 9268-9280. [doi:10.1016/j.eswa.2008.12.005]

Coello, C., Lechuga, M., 2002. MOPSO: A Proposal for Multiple Objective Particle Swarm Optimization. Proceedings of the Congress on Evolutionary Computation, Honolulu, HI, 2:1051-1056. [doi:10.1109/CEC.2002. 1004388]

Deb, K., Pratap, A., Agarwal, S., Meyarivan, T., 2002. A fast and elitist multi-objective genetic-algorithm: NSGA-II. IEEE Transactions on Evolutionary Computation, 6(2): 182-197. [doi:10.1109/4235.996017] 
D’Errico, G., Cerri, T., Pertusi, G., 2011. Multi-objective optimization of internal combustion engine by means of $1 \mathrm{D}$ fluid-dynamic models. Applied Energy, 88(3):767-777. [doi:10.1016/j.apenergy.2010.09.001]

Ghobadian, B., Rahimi, H., Nikbakht, A.M., Najafi, G., Yusaf, T.F., 2009. Diesel engine performance and exhaust emission analysis using waste cooking biodiesel fuel with an artificial neural network. Renewable Energy, 34(4): 976-982. [doi:10.1016/j.renene.2008.08.008]

Guerrier, M., Cawsey, P., 2004. The development of model based methodologies for gasoline IC engine calibration. SAE Technical Paper, No. 2004-01-1466. [doi:10.4271/ 2004-01-1466]

Hafner, M., Schuler, M., Nelles, O., Isermann, R., 2000. Fast neural networks for diesel engine control design. Control Engineering Practice, 8(11):1211-1221. [doi:10.1016/ S0967-0661(00)00057-5]

Ismail, H.M., Ng, H.K., Queck, C.W., Gan, S., 2012. Artificial neural networks modelling of engine-out responses for a light-duty diesel engine fuelled with biodiesel blends. Applied Energy, 92:769-777. [doi:10.1016/j.apenergy. 2011.08.027]

Kennedy, J., Heberhart, R., 1995. Particle Swarm Optimization. IEEE International Conference on Neural Networks, Perth, WA, 4:1942-1948. [doi:10.1109/ICNN.1995. 488968]

Kesgin, U., 2004. Genetic algorithm and artificial neural network for engine optimisation of efficiency and $\mathrm{NO}_{x}$ emission. Fuel, 83(7-8):885-895. [doi:10.1016/j.fuel. 2003.10.025]
Langouet, H., Métivier, L., Sinoquet, D., Huy, Q., 2011. Engine calibration: multi-objective constrained optimization of engine maps. Optimization and Engineering, 12(3): 407-424. [doi:10.1007/s11081-011-9140-8]

Mori, K., 1997. Worldwide trends in heavy-duty diesel engine exhaust emission legislation and compliance technologies. SAE Technical Paper, No. 970753. [doi:10.4271/ 970753]

Nelles, O., 2001. Nonlinear System Identification: from Classical Approaches to Neural Networks and Fuzzy Models. Springer, Berlin, p.365-389.

Saerens, B., Vandersteen, J., Persoons, T., Swevers, J., Diehl, M., Bulck, E., 2009. Minimization of the fuel consumption of a gasoline engine using dynamic optimization. Applied Energy, 86(9):1582-1588. [doi:10.1016/j.apenergy.2008.12.022]

Shi, Y., Reitz, R., 2010. Optimization of a heavy duty compression ignition engine fueled with diesel and gasolinelike fuels. Fuel, 89(11):3416-3430. [doi:10.1016/j.fuel. 2010.02.023]

Yap, W., Ho, T., Karri, V., 2012. Exhaust emissions control and engine parameters optimization using artificial neural network virtual sensors for a hydrogen-powered vehicle. International Journal of Hydrogen Energy, 37(10): 8704-8715. [doi:10.1016/j.ijhydene.2012.02.153]

Zhao, B., Cao, Y.J., 2005. Multiple objective particle swarm optimization technique for economic load dispatch. Journal of Zhejiang University SCIENCE, 6(5):420-427. [doi:10.1631/jzus.2005.A0420] 